\title{
Water Resources Conservancy and Risk Reduction Under Climatic Instability
}

\author{
Symeon E. Christodoulou
}

Received: 10 December 2010 / Accepted: 13 December 2010 /

Published online: 7 January 2011

(C) Springer Science+Business Media B.V. 2011

\section{Preface}

Nowadays, amidst global climatic change, extended periods of drought, heightened demand of water and increased urbanization, the development and application of scientific knowledge and integrated water resources management policies for sustainable management of aquatic resources is of paramount importance not only to national governments but also to transnational networks. Such scientific knowledge and policies should cover a myriad of issues related to water, ranging from water scarcity and conservancy, climate change and their effects on water, drought and floods to water quality, water recycling, water loss, wastewater treatment, commodification of water, and water pricing.

Discussing some of the aforementioned important components of sustainable management of aquatic resources and included herein, are selected manuscripts from the European Water Resources Association's (EWRA) Seventh International Conference on "Water Resources Conservancy and Risk Reduction Under Climatic Instability" held in Limassol, Cyprus (25-27 June 2009).

The conference, which was hosted by the University of Cyprus, aimed to provide an international forum for the exchange of scientific information and knowledgesharing on state-of-the-art research efforts and on contemporary water-related issues, on a multitude of thematic areas such as water-related natural hazards, water management and technologies, macro-engineering and environmental governance, proactive planning and crisis management, sustainable development, urban water supply systems, water losses, water shortage and water reuse, water pollution, climate change, and IWRM.

The work presented and included in the conference proceedings (ISBN 978-9963671-94-6) and selectively in this Special Issue of the Journal of Water Resources

S. E. Christodoulou $(\varangle)$

Department of Civil and Environmental Engineering, University of Cyprus,

P.O. Box 20537, 1678 Nicosia, Cyprus

e-mail: schristo@ucy.ac.cy 
Management constitutes an excellent blending of cutting-edge research, of scientific and applied knowledge and of case-studies across the globe. This body of knowledge should be of great interest to both researchers and practitioners since it offers the European and the international community of water professionals at large a great opportunity to experience the latest achievements in water-related research, science, practice and management.

The work by Kourakos and Mantoglou on the simulation and multi-objective management of coastal aquifers in semi-arid regions investigates the impact of prolonged droughts on coastal aquifers by assuming various scenarios of reduced groundwater recharge and by simulating water flow and quality in the coastal aquifer using a three-dimensional, variable density, finite difference model (SEAWAT) which is then utilized in developing trade-off curves (Pareto fronts) for each drought scenario. As the authors conclude, the trade-off curves indicate an increase on the economic and environmental cost as groundwater recharge reduces due to climate change.

In the work by Raziei et al., the applicability of GPCC and NCEP/NCAR precipitation datasets for drought analysis is investigated as the means to overcome the lack of reliable and updated precipitation datasets and for the purpose of establishing a drought monitoring and early warning system in Iran.

Vasiliades et al. investigate hydrological drought characteristics using a water balance derived drought index, as applied to the Pinios river basin (Thessaly, Greece) and by adopting the concept of hydrological management at the sub-watershed scale. Fourteen (14) sub-watersheds of Pinios river basin were delineated according to the major tributaries and, for the assessment of hydrological drought, a six-parameter monthly conceptual water balance model (UTHBAL model) was applied regionally to simulate runoff. The results showed that the water balance derived drought index is a good indicator of hydrological drought in all sub-watersheds, since it is capable of quantifying drought severity and duration. On the same thematic area of water shortage, Tsakiris and Spiliotis present a multi-criteria method incorporating a fuzzy set approach and the 0/1 programming for selecting the most appropriate actions in conditions of long-term water scarcity and under a set of objectives and constraints. The method proposed by the authors, which also includes the right of veto which can be utilized under certain extreme conditions or for securing commensurate solutions, was applied to the island of Naxos, Cyclades (Greece) as a case-study.

Changing thematic area, from aquifers, water-related natural hazards and water shortage to water systems, we find the contribution by Kargas and Kerkides on the study of the phenomenon of horizontal infiltration. An attempt is made by the researchers to compare experimental soil moisture profiles for a horizontal infiltration experiment with calculated profiles obtained variously through the use of the computation code of HYDRUS 1D and through the semi-analytical solution of the appropriate diffusion equation when the soil water diffusivity is obtained directly from the experimental data. On a related topic, groundwater management is the focus of the work by Trichakis et al. on the modeling for karstic groundwater level simulation based on artificial neural networks (ANN). The authors, upon using available measured data from the Edward's aquifer in Texas, USA to train and evaluate a proposed ANN, they then focus on the simulation of hydraulic head change and on checking the ability of the ANN to interpolate or extrapolate knowledge in other regions. 
Moving to the thematic area of wastewater treatment and reuse, we find the works of Alfarra et al. on a proposed framework for wastewater reuse in Jordan, and of Xanthos et al. on the performance assessment of secondary settling tanks using CFD modeling. Alfarra et al. look at the pressing water scarcity in Jordan and the increase in the demands of marginal water resources for the agricultural sector, offering a framework for wastewater reuse as a possible alleviating solution. Their proposed approach builds on a project related to the Sustainable Management of Available Water Resources with Innovative Technologies (SMART) funded by the German Federal Ministry for Education and Research in Germany, introducing a wastewater reuse index (WRI) that reflects the actual proportion of wastewater reused from the total generated wastewater. Xanthos et al. investigate the performance of a particular and very important system component in wastewater treatment plants, namely secondary settling tanks. Recognizing that amongst the principal separation processes used to treat effluents in the water industry is the sedimentation of solid particulates from the carrier fluid known as mixed liquor by the force of gravity, and utilizing New York City's Department of Environmental Protection (DEP) data from its Upper East River water pollution control plants, the authors investigate the use of a 3D Computational Fluid Dynamics (CFD) model to illustrate how different modeling approaches applied on the physical phenomena that take place in the tank affect the outcome of a CFD model and its predictions. Their model has been used as a tool to assess the internal behavior of such baffles and assess the clarifier's performance based on different inlet baffle configurations.

Water pollution and water quality is the focus of the papers by Fatta-Kassinos et al., Tiehm et al., Kostarelos et al., and Eliades et al. Fatta-Kassinos et al. report on the existence of pharmaceutical compounds in tertiary treated urban wastewater that is utilized for reuse applications. Starting from the acknowledgment that in the last several years there has been a growing level of concern related to the hypothesis that various chemicals may exhibit endocrine disrupting effects and that thousands of tons of pharmacologically active substances used annually by the general population end up in the wastewaters, the authors raise their concern on the existence of xenobiotic compounds in the tertiary treated wastewaters. Their research study describes the application of a recently developed multi-residue method for the determination of 29 multi-class pharmaceuticals using off line solid phase extraction followed by liquid chromatography-triple quadrupole mass spectrometry (LC-MS-MS). The method was applied for the analysis of pharmaceutical residues at three sewage treatment plants in Cyprus serving major coastal Mediterranean cities, concluding that the biological treatment step contributes the most to the removal of the compounds while sand filtration and chlorination steps reduce slightly the residual concentrations. Biodegradation of pharmaceutical compounds was also the topic of the study by Tiehm et al., in relation to the occurrence of such compounds in the Jordan Valley. The objectives of their study were (1) to assess the occurrence of emerging pollutants in the Jordan valley and (2) to review and examine the biodegradability of selected key compounds. Results demonstrated biodegradation for pharmaceutical residues, with the degradation rate faster in treated wastewater as compared to raw wastewater. On a related topic, Kostarelos et al. present a field study of catch basin inserts for the removal of pollutants from urban runoff. Their focus is on non-point source (NPS) pollution which, unlike point source pollution from domestic and industrial wastewater treatment plants, comes from many diffuse sources and represents the 
main cause of contamination of many rivers, streams and other water bodies of many developed countries. In their study, six commercially-available CBIs were installed and monitored at sites along highways in Westchester County (New York) and their performance subsequently analyzed. The topic of water quality couldn't be complete without linkage to water security. This is the focus of the work by Eliades et al., in which a security-oriented manual quality sampling methodology for water systems is presented. As the authors note, the management and security of water resources will be a key challenge in the years ahead, especially in relation to drinking water distribution networks. The authors' contribution is on formulating the problem based on substance propagation dynamics and coupled with the impact dynamics describing the damage caused by a contamination in a drinking water distribution network. The proposed solution methodology optimizes a risk-objective, in order to compute a manual sampling scheme comprised of sampling nodes and times, using evolutionary computation techniques.

Urban water distribution networks (UWDN) is the focus of the last two papers, by Christodoulou and by Bimpas et al. Christodoulou presents a framework for devising a proactive risk-based integrity-monitoring strategy for the management of UWDN. The framework presented is based on a combination of artificial neural network, parametric and nonparametric survival analysis and it is utilized in the estimation of time-to-failure metrics for pipe networks. The paper presents results from a case-study application in Limassol (Cyprus). In contrast to Christodoulou's use of historical breakage data, Bimpas et al. investigate the use of real-time data for assessing the vulnerability of UWDN and detecting leakages. They present the design and implementation of an integrated high-resolution imaging ground penetrating radar for water pipeline rehabilitation. The equipment and associated decision support system were developed in the framework of the European research initiative WATERPIPE. 